\title{
Short-term climate response to a freshwater pulse in the Southern Ocean
}

\author{
Glen Richardson, Martin R. Wadley, and Karen J. Heywood \\ School of Environmental Sciences, University of East Anglia, Norwich, UK
}

David P. Stevens

School of Mathematics, University of East Anglia, Norwich, UK

Helene T. Banks

Hadley Centre, UK Met Office, Exeter, UK

Received 21 September 2004; revised 11 November 2004; accepted 9 December 2004; published 1 February 2005.

[1] The short-term response of the climate system to a freshwater anomaly in the Southern Ocean is investigated using a coupled global climate model. As a result of the anomaly, ventilation of deep waters around Antarctica is inhibited, causing a warming of the deep ocean, and a cooling of the surface. The surface cooling causes Antarctic sea-ice to thicken and increase in extent, and this leads to a cooling of Southern Hemisphere surface air temperature. The surface cooling increases over the first 5 years, then remains constant over the next 5 years. There is a more rapid response in the Pacific Ocean, which transmits a signal to the Northern Hemisphere, ultimately causing a shift to the negative phase of the North Atlantic Oscillation in years 5-10. Citation: Richardson, G., M. R. Wadley, K. J. Heywood, D. P. Stevens, and H. T. Banks (2005), Short-term climate response to a freshwater pulse in the Southern Ocean, Geophys. Res. Lett., 32, L03702, doi:10.1029/2004GL021586.

\section{Introduction}

[2] The oceans play a central role in controlling the global climate by transporting and storing heat. For example, it has been estimated that ocean heat transport is responsible for warming the mean temperature of Western Europe by $6^{\circ} \mathrm{C}$ [Seager et al., 2002]. Ocean heat transport in the Atlantic Ocean is dominated by the meridional overturning circulation (MOC), which is dependent not only on the formation of North Atlantic Deep Water (NADW), but also on processes in the Southern Ocean. Antarctic Bottom Water (AABW) and Antarctic Intermediate Water (AAIW) form in the Southern Ocean, and NADW returns to the upper ocean as Circumpolar Deep Water [Speer et al., 2000]. The Southern Ocean's central role in the global circulation makes it probable that any changes occurring there would have global impacts.

[3] There is considerable uncertainty with regard to what might happen in Antarctica in future climate scenarios [Oppenheimer and Alley, 2004]. One scenario as outlined by Oppenheimer [1998] is that the Ross Ice Shelf could disintegrate within 50-200 years. The resultant discharge of freshwater into the surface layers of the Southern Ocean could affect global climate by impacting on the global

Copyright 2005 by the American Geophysical Union. 0094-8276/05/2004GL021586\$05.00 thermohaline circulation. Weaver et al. [2003] proposed that a large meltwater pulse from Antarctica triggered a sudden warming during the last deglaciation.

[4] Several studies in recent years have investigated the impacts of a shut down of the North Atlantic MOC [Manabe and Stouffer, 1995; Vellinga and Wood, 2002; Dong and Sutton, 2002]. These model-based experiments shut down the North Atlantic cell of the MOC by adding freshwater to the surface layers of the North Atlantic. Vellinga and Wood [2002] found that thirty years after a freshwater pulse, the Northern Hemisphere surface air temperature (SAT) had cooled by over $1^{\circ} \mathrm{C}$, with localised cooling of up to $8^{\circ} \mathrm{C}$, while the South Atlantic region had warmed by around $1^{\circ} \mathrm{C}$. Dong and Sutton [2002] found that significant impacts spread to the Southern Hemisphere within a decade. This rapid spread is made possible by the southward propagation of Kelvin waves along the west coast of the Atlantic, and then along the equator. Knuttl et al. [2004] found that freshwater forcing in the North Atlantic had a direct impact on Southern Ocean temperature on millennial timescales, via anomalous southward oceanic heat transport. They also cited Kelvin waves as the mechanism for the initial adjustment process.

[5] Complementary perturbation experiments on decadal timescales using fully coupled ocean-ice-atmosphere global climate models (GCMs) have not been conducted in the Southern Ocean. However, some experiments of this type have been conducted using either different types of models or over different timescales. Weaver et al. [2003], using a model of intermediate complexity, added freshwater to specific areas known to be formation regions of AAIW and AABW. They found that as the density of AAIW and AABW decreased, the formation of NADW intensified. After 500 years the North Atlantic region was warmed by up to $5^{\circ} \mathrm{C}$, while large areas of the Southern Hemisphere were significantly cooled, by as much as $7^{\circ} \mathrm{C}$ when the formation regions of AABW were freshened. Ivchenko et al. [2004] used an ocean model to investigate the immediate response to positive salinity anomalies in the Southern Ocean. They found significant temperature anomalies at the equator within months of their initial disturbance, and proposed a fast wave response in the South Pacific as the mechanism by which the signal propagates to the tropics.

[6] As well as these modelling experiments, remote sensing and reanalysis data have also been studied for links 
a)

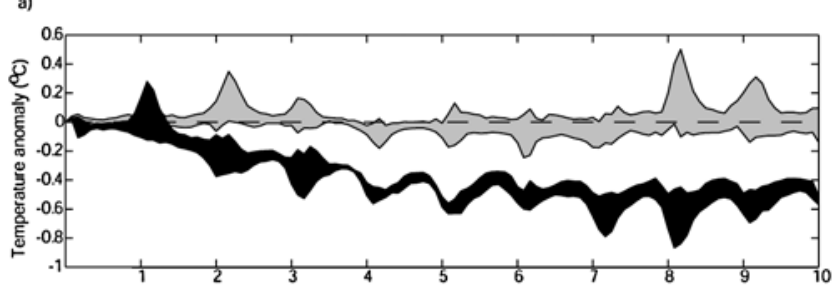

b)

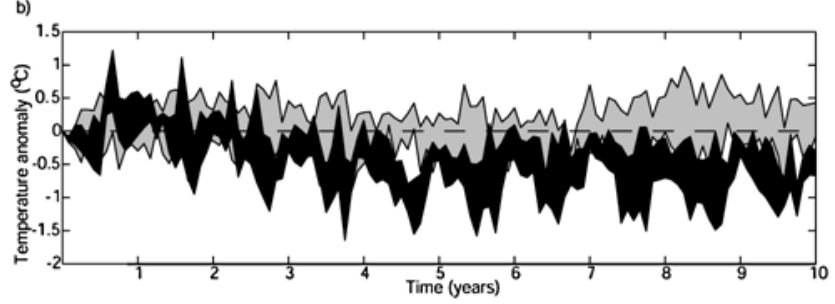

Figure 1. (a) Monthly mean sea surface temperature $\left({ }^{\circ} \mathrm{C}\right)$ anomalies south of $40^{\circ} \mathrm{S}$, and (b) monthly mean Southern Hemisphere surface air temperature $\left({ }^{\circ} \mathrm{C}\right)$ anomalies, over the ten years of the simulation. Light (dark) shading shows the envelope of variability in the control (perturbed) ensemble. The mean seasonal cycle of the control run has been removed from all series.

between the Southern Ocean and the wider global climate. Kwok and Comiso [2002] found strong correlations between the Southern Oscillation Index and polar climate. In particular it was found that sea-ice in the Bellingshausen and Amundsen Seas retreated during El Nino events. Yuan and Martinson [2000] found a teleconnection between these seas and the western-central tropical Pacific. These papers suggest that it is the Southern Ocean that is reacting to changes elsewhere, rather than the Southern Ocean forcing the climate at lower latitudes.

[7] The aim of this experiment is to investigate the response of the global climate system in the first decade following an instantaneous freshwater input in the Southern Ocean, using a fully coupled GCM.

\section{Model and Method}

[8] The model used is the UK Met Office global coupled ocean-atmosphere general circulation model HadCM3 [Gordon et al., 2000]. The atmospheric component has a horizontal resolution of $2.5^{\circ} \times 3.75^{\circ}$, with 19 vertical levels. The ocean has a $1.25^{\circ} \times 1.25^{\circ}$ grid with 20 vertical levels. The model represents sea-ice processes explicitly, simulates aspects of climate variability such as ENSO, and requires no flux adjustments to maintain a stable climate.

[9] Here, we use HadCM3 to simulate the impact of a salinity perturbation in the Southern Ocean. We performed a ten-year control simulation, starting in January, with initial conditions taken from a multi-century integration of the model. We then ran a perturbed simulation, starting with identical initial conditions, except for the salinity perturbation which consisted of an instantaneous reduction, by 1 , in the salinity of the upper $666 \mathrm{~m}$ of ocean everywhere south of $65^{\circ} \mathrm{S}$. This is equivalent to $1.677 \times 10^{14} \mathrm{~m}^{3}$ of freshwater, or around $0.6 \%$ of the estimated total volume of the Antarctic Ice Sheets [Church et al., 2001]. The location of the anomaly was chosen to cover all areas where bottom waters sink in this model. The sinking locations were found by following a tracer introduced at the surface. The depth of the anomaly was chosen to be compatible with Northern Hemisphere studies with this model, and to encompass the deepest winter mixed layers in this region. In order to separate the impacts of the perturbation from internal variability, we performed ensembles of five integrations of both the control and perturbed simulations. The members of each ensemble were started from identical ocean conditions, but slightly different atmospheric conditions, following the technique of Collins et al. [2002]. After the initial freshening, the perturbed simulations were allowed to run for ten years without further interference.

\section{Results}

[10] The strongest response is a cooling of the Southern Hemisphere middle and high latitudes (Figure 1). The sea surface temperature (SST) in the Southern Ocean decreases for the first five years, after which time the cooling remains at around $0.5^{\circ} \mathrm{C}$ (Figure 1a). The Southern Hemisphere surface air temperature (SAT) has a similar cooling trend until year five, with the cooling again stabilizing at around $0.5^{\circ} \mathrm{C}$ for the rest of the decade (Figure $1 \mathrm{~b}$ ). This cooling is largely confined to the region south of $40^{\circ} \mathrm{S}$ (Figure 2). The response in the Northern Hemisphere is more regional, with localised areas of warming and cooling but no hemispherescale temperature trend. The largest statistically significant impacts are a cooling of around $0.5^{\circ} \mathrm{C}$ in the Northeast Pacific and warming in the North Atlantic, with warming in excess of $1^{\circ} \mathrm{C}$ in the Labrador Sea area (Figure 2).

[11] Spatially, the greatest SAT anomalies coincide with the greatest changes in sea-ice. The extent and thickness of Antarctic sea-ice is increased in the perturbed runs in all seasons (Figure 3), with winter and spring showing the largest increases over the control climate. In the Northern Hemisphere sea-ice retreats in the Labrador Sea, but elsewhere changes are not significant.

[12] Both the SST and SAT anomalies in Figure 1 exhibit seasonal cycles, which are in opposite phase. The SST anomaly is reduced in winter because, over a large part of the area, the sea surface is already at or near freezing point, and thus cannot cool any further. In the summer, the SST in

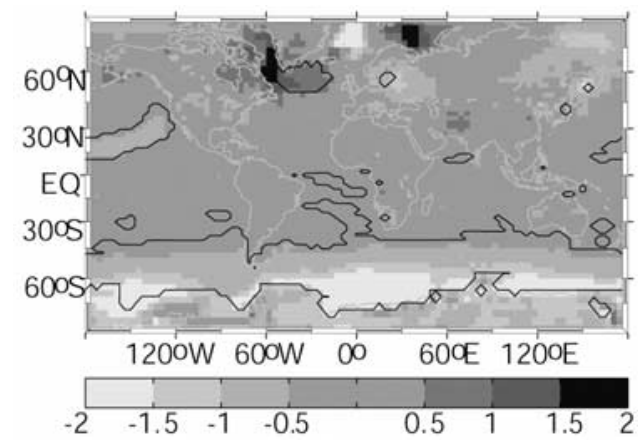

Figure 2. Surface air temperature $\left({ }^{\circ} \mathrm{C}\right.$ ) anomalies (mean of perturbed ensemble - mean of control ensemble), averaged over years $6-10$ of simulation. Contour indicates areas where the anomaly is $95 \%$ significant using Student's t-test. See color version of this figure in the HTML. 


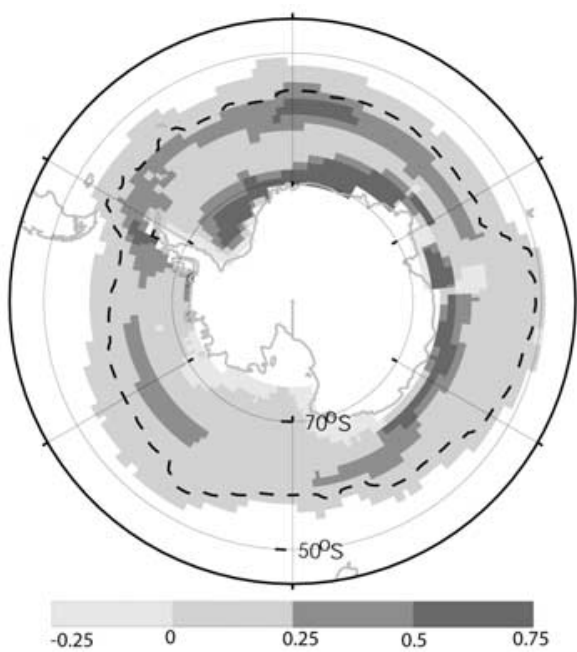

Figure 3. Mean Antarctic sea-ice thickness (m) anomalies (mean of perturbed ensemble - mean of control ensemble), averaged over years 6-10 of simulation. Dashed contour indicates northern limit of sea-ice in control run. See color version of this figure in the HTML.

the control simulations rises above freezing over a larger area, making it possible for larger differences to occur. The SAT cooling exhibits a larger seasonal cycle and is greatest in the Southern Hemisphere winter-spring months. This is because in the winter, the air is generally warmed by the sea. However, in the perturbed experiments, a layer of sea-ice inhibits this heat flux. Hence the seasons with greatest sea-ice anomalies see the greatest reduction in SAT. The North Atlantic warming is greatest in the northern winter, when the sea-ice retreat is at its peak.

[13] The cooling in the Southern Ocean is restricted to the upper $700 \mathrm{~m}$ (Figure 4). Below that depth, anomalously warm water builds up throughout the decade, which is circumpolar in extent. The maximum warming occurs beneath the initial salinity anomaly. The warming signal has spread down to the seabed by year two, then propagates northward at depths greater than $3000 \mathrm{~m}$. The magnitude of the deep warming is around $0.05^{\circ} \mathrm{C}$, which is statistically significant due to the minimal natural variability at this depth. By year ten, there is also an indication of a warming throughout much of the water column at around $60^{\circ} \mathrm{N}$.

[14] There are also significant changes in the Antarctic Circumpolar Current (ACC) and in sea-level pressure (SLP). The mean volume transport of the ACC in this model is around $220 \mathrm{~Sv}\left(1 \mathrm{~Sv}=10^{6} \mathrm{~m}^{3} \mathrm{~s}^{-1}\right)$, with a natural variability of $\pm 7 \mathrm{~Sv}$. On addition of the freshwater the transport reduces almost immediately by around $10 \mathrm{~Sv}$, due to the decrease in meridional density gradient. There does not appear to be any significant change to the Southern Annular Mode [Thompson and Solomon, 2002] in the ten years following the salinity perturbation. However, over years 6-10 of the simulation, SLP increases significantly over the Arctic, and decreases in the North Atlantic.

\section{Discussion}

[15] At first glance, the results appear similar to those experiments investigating a freshwater pulse in the North
Atlantic, with a strong cooling in the lower atmosphere and upper ocean in the hemisphere of the perturbation. However, the mechanism causing this response is quite different. In the North Atlantic the warm waters transporting heat poleward are near the ocean surface, whereas in the Southern Ocean the warm waters transporting heat poleward are at greater depths. In the North Atlantic experiments, the main mechanism was an immediate shut down of the Atlantic MOC, which halted the northward transport of heat. In this experiment, the impact on the MOC has been much smaller. By the end of the year ten, the strength of the AABW overturning cell has decreased by around $1 \mathrm{~Sv}(5 \%)$.

[16] The cause of the cooling in the Southern Hemisphere appears to be a more local effect, associated with the upwelling of warm deep water, rather than the sinking of cold dense water. The widespread cooling of the ocean surface is underlain by a warm anomaly (Figure 4), which warms and spreads throughout the decade. This is due to stratification of the upper ocean caused by the freshwater pulse. The magnitude of vertical velocity at the base of the salinity anomaly is reduced by $27 \%$, averaged over the full ten years. This reduction in vertical motion appears to be buoyancy driven, as the mixed layer depth is significantly reduced in many areas, while any change in the zonally averaged wind stress curl, and thus Ekman pumping, is negligible. The stratification traps the warmer deep water below the surface layers, which are cut off from this heat source. The cooling of the ocean surface leads to increased sea-ice, which reduces the heat flux to the atmosphere south of $60^{\circ} \mathrm{S}$ from a mean value of $33 \mathrm{Wm}^{-2}$ in the control run, to $28 \mathrm{Wm}^{-2}$ in the perturbed run, averaged over the full ten years. The atmospheric cooling is greatest in winter-spring, when the sea-ice anomalies are also greatest.

[17] The impacts in the Northern Hemisphere give the appearance of an NAO signal. An increase in SLP over the Arctic, warming over the Labrador and Irminger Seas, and cooling over the Greenland Sea are all indicative of a shift to the negative phase [Hurrell et al., 2001; Dickson et al., 1996]. It is unlikely that any signal is transmitted to the North Atlantic via the deep ocean. The changes in the

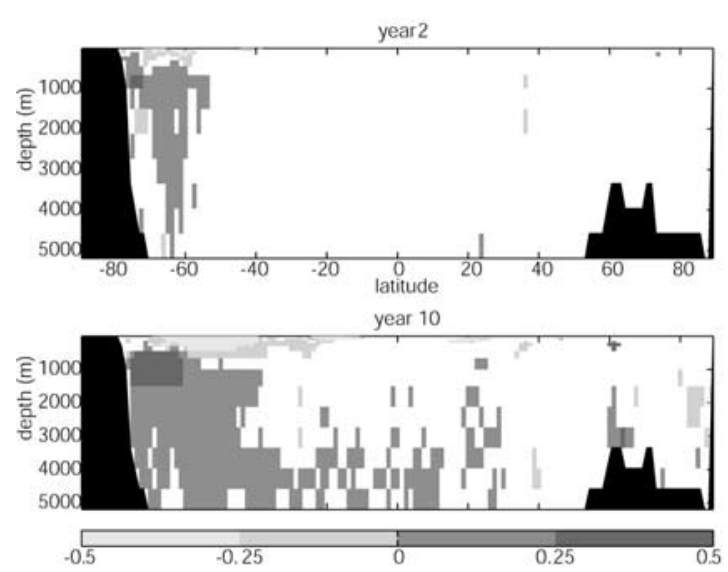

Figure 4. Zonal mean ocean temperature $\left({ }^{\circ} \mathrm{C}\right)$ anomalies (mean of perturbed ensemble - mean of control ensemble) in years 2 and 10 of simulation. Only anomalies significant at $95 \%$ level are shown. See color version of this figure in the HTML. 


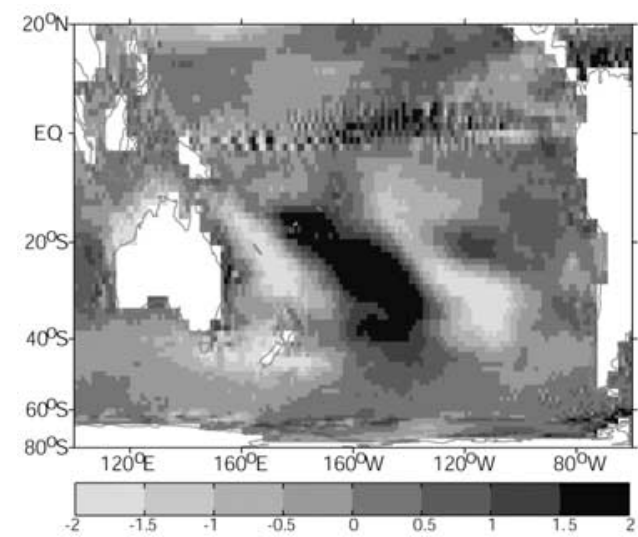

Figure 5. Sea surface temperature $\left({ }^{\circ} \mathrm{C}\right)$ anomalies (perturbed - control) in the South Pacific, after 101 days. See color version of this figure in the HTML.

strength of the North Atlantic overturning are smaller than the natural variability in the model. Therefore we must look for an alternative mechanism that can transmit a signal from the Southern Ocean to the Northern Hemisphere in less than a decade. By analysing animations of daily SST and surface currents during the first 6 months of our experiment, we can see evidence of the link between Southern Ocean anomalies and the equatorial ocean proposed by Ivchenko et al. [2004]. They found that interaction of a positive salinity anomaly with the topography of Drake Passage generates barotropic Rossby waves which propagate across the Pacific. At the western boundary, Kelvin waves are induced, which propagate northward and then along the equator to the eastern boundary. In our experiment, from around one month after the perturbation, we see regions of anomalous warm and cold water forming across the tropical South Pacific (Figure 5), similar to the feature shown in Figure 1 of Ivchenko et al. [2004]. These temperature anomalies are associated with anomalous temperature advection, caused by wave-like meridional current anomalies. During months 2-6, warm and cold anomalies can be seen propagating eastward along the equator. The South Pacific is the only area where there are coherent significant SST anomalies in the months following the salinity perturbation. Analysis of surface heat fluxes indicates that these SST changes are not driven by the atmosphere. Therefore we infer that the signal reaches the tropical Pacific via an oceanic mechanism. The response we observe differs from that of Ivchenko et al. [2004] in both timing and magnitude. This is to be expected, given the different models and experimental setup. However, the results are similar enough to make us believe that we are seeing the same response and that a rapid equatorial response to a Southern Ocean anomaly is real. Once the signal has reached the equator, the response becomes global. Links between tropical SSTs and extratropical climate have become well established in recent years. Hoerling et al. [2001] proposed a link between tropical Pacific SST and the NAO, while Mathieu et al. [2004] found that El Nino events have a significant influence on the climate of the North Atlantic region. Months 7 to 12 of all our perturbed simulations are marked by extensive warming in the Eastern Pacific. Quite why this should ultimately lead to a shift to the negative phase of the NAO is not clear, and will be the subject of future research. Further model runs and analysis will be required to determine conclusively whether the signal is transmitted via the ocean or atmosphere. What is clear is that a large enough freshwater pulse in the Southern Ocean can, at least in one coupled GCM, have global impacts within 10 years.

[18] Acknowledgments. This work was supported by the UK Natural Environmental Research Council under the thematic programme: Coupled Ocean Atmosphere Processes and European Climate. Glen Richardson is also supported by a CASE partnership with the UK Met Office. We thank the two referees for their constructive comments on the manuscript.

\section{References}

Church, J. A., J. M. Gregory, P. Huybrechts, M. Kuhn, K. Lambeck, M. T. Nhuan, D. Qin, and P. L. Woodworth (2001), Changes in sea level, in Climate Change 2001: The Scientific Basis: Contribution of Working Group I to the Third Assessment Report of the Intergovernmental Panel on Climate Change, pp. 639-693, Cambridge Univ. Press, New York.

Collins, M., D. Frame, B. Sinha, and C. Wilson (2002), How far ahead could we predict El Nino?, Geophys. Res. Lett., 29(10), 1492, doi:10.1029/2001GL013919.

Dickson, R., J. Lazier, J. Meincke, P. Rhines, and J. Swift (1996), Longterm co-ordinated changes in the convective activity of the North Atlantic, Prog. Oceanogr., 38, 241-295.

Dong, B. W., and R. T. Sutton (2002), Adjustment of the coupled oceanatmosphere system to a sudden change in the Thermohaline Circulation, Geophys. Res. Lett., 29(15), 1728, doi:10.1029/2002GL015229.

Gordon, C., C. Cooper, C. A. Senior, H. Banks, J. M. Gregory, T. C. Johns, J. F. B. Mitchell, and R. A. Wood (2000), The simulation of SST, sea ice extent and ocean heat transports in a version of the Hadley Centre coupled model without flux adjustments, Clim. Dyn., 16, 147-168.

Hoerling, M. P., J. W. Hurrell, and T. Y. Xu (2001), Tropical origins for recent North Atlantic climate change, Science, 292, 90-92.

Hurrell, J. W., Y. Kushnir, and M. Visbeck (2001), Climate-The North Atlantic oscillation, Science, 291, 603-605.

Ivchenko, V. O., V. B. Zalesny, and M. R. Drinkwater (2004), Can the equatorial ocean quickly respond to Antarctic sea ice/salinity anomalies?, Geophys. Res. Lett., 31, L15310, doi:10.1029/2004GL020472.

Knuttl, R., J. Fluckiger, T. F. Stocker, and A. Timmermann (2004), Strong hemispheric coupling of glacial climate through freshwater discharge and ocean circulation, Nature, 430, 851-856.

Kwok, R., and J. C. Comiso (2002), Southern Ocean climate and sea ice anomalies associated with Southern Oscillation, J. Clim., 15, 487-501.

Manabe, S., and R. J. Stouffer (1995), Simulation of abrupt climate-change induced by fresh-water input to the North Atlantic Ocean, Nature, 378, $165-167$

Mathieu, P. P., R. T. Sutton, B. W. Dong, and M. Collins (2004), Predictability of winter climate over the North Atlantic European region during ENSO events, J. Clim., 17, 1953-1974.

Oppenheimer, M. (1998), Global warming and the stability of the West Antarctic Ice Sheet, Nature, 393, 325-332.

Oppenheimer, M., and R. B. Alley (2004), The West Antarctic Ice Sheet and long term climate policy-An editorial comment, Clim. Change, 64, $1-10$.

Seager, R., D. S. Battisti, J. Yin, N. Gordon, N. Naik, A. C. Clement, and M. A. Cane (2002), Is the Gulf Stream responsible for Europe's mild winters?, Q. J. R. Meteorol. Soc., 128, 2563-2586.

Speer, K., S. R. Rintoul, and B. Sloyan (2000), The diabatic Deacon Cell, J. Phys. Oceanogr., 30, 3212-3222.

Thompson, D. W. J., and S. Solomon (2002), Interpretation of recent Southern Hemisphere climate change, Science, 296, 895-899.

Vellinga, M., and R. A. Wood (2002), Global climatic impacts of a collapse of the Atlantic thermohaline circulation, Clim. Change, 54, 251-267.

Weaver, A. J., O. A. Saenko, P. U. Clark, and J. X. Mitrovica (2003), Meltwater pulse 1-A from Antarctica as a trigger of the bolling-allerod warm interval, Science, 299, 1709-1713.

Yuan, X., and D. G. Martinson (2000), Antarctic sea ice extent variability and its global connectivity, J. Clim., 13, 1697-1717.

H. T. Banks, Hadley Centre, UK Met Office, Exeter EX1 3PB, UK

K. J. Heywood, G. Richardson, and M. R. Wadley, School of Environmental Sciences, University of East Anglia, Norwich NR4 7TJ, UK. (g.richardson@uea.ac.uk)

D. P. Stevens, School of Mathematics, University of East Anglia, Norwich NR4 7TJ, UK. 